\title{
EFFECT OF POTASSIUM-PERMANGANATE MODIFICATION ON THE MICROSTRUCTURE AND ADSORPTION PROPERTY OF ACTIVATED CARBON
}

\author{
VPLIV MODIFIKACIJE S KALIJEVIM PERMANGANATOM NA \\ MIKROSTRUKTURO IN ADSORPCIJSKE LASTNOSTI \\ AKTIVIRANEGA OGLJIKA
}

\author{
Zhifu Wu ${ }^{1}$, Peilin Qing1, Guiquan $\mathbf{G u o}^{2}$, Bingfang Shi ${ }^{1 *}$, Qiaohong $\mathbf{H u}^{2}$ \\ ${ }^{1}$ School of Materials Science and Engineering, Baise University, Guangxi Baise 533000, China \\ ${ }^{2}$ School of Chemistry and Chemical Engineering, Xingtai University, No. 88, Quanbei East Street, Qiaodong District, Xingtai 054001, China
}

Prejem rokopisa - received: 2019-03-28; sprejem za objavo - accepted for publication: 2019-07-03

doi: $10.17222 /$ mit. 2019.068

\begin{abstract}
Potassium permanganate was loaded onto activated carbon using the impregnation method to obtain modified activated carbon. The activated carbon and activated carbon loaded with potassium permanganate were then placed in a closed, newly decorated house. It was found that formaldehyde amount decreased sharply after the adsorption of the activated carbon, and further decreased after the adsorption of the activated carbon modified with potassium permanganate. By measuring the amount of formaldehyde in the room before and after the adsorption of the activated carbon, the adsorption capacity of the two with respect to formaldehyde was compared. The experimental results showed that the adsorption capacity of the potassium-permanganate-modified activated carbon increased significantly. A specific-surface-area and porosity analyzer, field-emission scanning electron microscope, transmission electron microscope and powder X-ray diffractometer were used to characterize the activated carbon modified with potassium permanganate. The specific surface area of the activated carbon modified with potassium permanganate increased significantly, the number of micropores increased and the pore size decreased. In addition, the mechanism of its adsorption of formaldehyde was discussed.

Keywords: formaldehyde, modification, potassium permanganate, activated carbon
\end{abstract}

Avtorji prispevka so kalijev permanganat nanesli na aktivirani ogljik z impregnacijsko metodo zato, da bi ga s tem modificirali. Aktivirano oglje in aktivirani ogljik v prisotnosti kalijevega permanganata so nato postavili v zaprto, na novo opremljeno hišo. Ugotovili so, da vsebnost formaldehida strmo pade po adsorpciji z aktiviranim ogljikom in še bolj, ko je prisoten aktivirani ogljik, modificiran s kalijevim permanganatom. Meritve adsorpcijske kapacitete za formaldehid v sobi, pred in po adsorpciji z aktiviranim ogljikom, so izvedli primerjalno za obe vrsti aktiviranega ogljika. Eksperimentalni rezultati so pokazali, da je adsorpcijska kapaciteta za formaldehid močno narasla v prisotnosti ogljika, aktiviranega s kalijevim permanganatom. Za karakterizacijo obeh vrst aktiviranega ogljika so uporabili merilnik specifične površine preseka, analizator poroznosti, vrstični elektronski mikroskop na poljsko emisijo, presevni elektronski mikroskop in praškovni rentgenski difraktometer. Specifična površina aktiviranega ogljika, modificiranega s kalijevim permanganatom, se je znatno povečala, število mikropor je naraslo in velikost por se je zmanjšala. Avtorji v članku razpravljajo tudi o mehanizmih adsorpcije formaldehida na njem.

Ključne besede: formaldehid, modifikacija, kalijev permanganat, aktivirani ogljik

\section{INTRODUCTION}

According to a survey, more than $80 \%$ of the time of humans is spent indoors. So the indoor-air quality is directly related to people's health. Formaldehyde is one of the most common indoor air pollutants, and the removal of formaldehyde is an extremely important task, especially in developing countries. This kind of harmful gas is mainly derived from adhesives, indoor furniture with artificial boards as raw materials, wallpaper, paints and other decorative materials. ${ }^{1,2}$ Long-time exposure to low-dose formaldehyde can easily lead to chronic respiratory diseases, neonatal physical deterioration, pregnancy syndrome and even cancer. A high concentration of formaldehyde is harmful to the human nervous system, immune system and liver. Epidemiological

*Corresponding author's e-mail:

Shibingfang@126.com, 1781177844@qq.com (Bingfang Shi) studies show that people who are exposed to formaldehyde for a long time are prone to cancer of the nasopharynx, skin and digestive tract. Therefore, the harmful effect of indoor formaldehyde has attracted more and more attention. ${ }^{3-6}$ The present treatment technologies of indoor formaldehyde pollution mainly include ozone oxidation, ${ }^{7,8}$ photocatalytic oxidation, ${ }^{9-14}$ the adsorption method, ${ }^{15,16}$ plant-absorption method ${ }^{17,18}$ and metal-oxide method. The adsorption method is characterized by high speed, convenience and low cost. The adsorption methods mainly include physical adsorption and chemical adsorption. The most commonly used sorbents for physical adsorption are granular activated carbon and activated carbon fiber. ${ }^{19}$ The chemical adsorbents usually include modified activated carbon, ${ }^{20,21}$ and activated carbon is originally an excellent adsorption material. Products modified with various methods have the characteristics of a strong selectivity and stability. 
These products not only have a large specific surface area and a suitable pore-size distribution, but also surface functional groups. The heat resistance, acid resistance and alkali resistance of activated carbon were further improved. Most importantly, the activated carbon modified during our experiment can avoid two times the pollution, and the effect of its repeated use after a hot regeneration is even better. This paper reports on the use of activated carbon as the carrier for potassium permanganate using impregnation. The effect of the activated carbon modified with potassium permanganate on the indoor-formaldehyde removal is studied, and the mechanism of removing formaldehyde with activated carbon and modified activated carbon is discussed.

\section{EXPERIMENTAL PART}

\subsection{Reagents and instruments}

Activated carbon, analytical pure formaldehyde solution (37-40 \%, Tianjin Wind Ship Chemical Reagent Company), potassium permanganate (Shanghai Pharmaceutical Reagent Co. Ltd., analytically pure), distilled water, a Panako multifunctional powder X-ray diffractometer (a test voltage of $40 \mathrm{kV}$, a current of $20 \mathrm{~mA}$, a scanning speed of $0.03^{\circ} \mathrm{s}$, continuous scan, 10-80 , $\mathrm{Cu}-K_{\alpha}(\lambda=0.15418 \mathrm{~nm})$, an McGeMINI VII 2390 automatic specific surface and porosity analyzer (gas adsorption time of $2 \mathrm{~h}$, temperature of $200{ }^{\circ} \mathrm{C}$ ), a JEOLJSM-6701F field-emission scanning electron microscope, a transmission electron microscope (FEI TACNAI TF20) and a Xuzhou Xingke six-in-one formaldehyde detector (Xuzhou Xingke Instrument Co., Ltd) were used.

\subsection{Preparation of the activated carbon loaded with potassium permanganate}

The activated carbon loaded with potassium permanganate was prepared by soaking a certain amount of activated carbon in a $0.079 \mathrm{~mol} \cdot \mathrm{L}^{-1}$ potassium-permanganate solution, oscillating it in an ultrasonic oscillator for $2 \mathrm{~h}$, drying it at $100{ }^{\circ} \mathrm{C}$ and taking it out after cooling.

\subsection{Determination of the iodine value of the activated carbon}

A dry activated-carbon sample of $0.5 \mathrm{~g}$ was moved into a $100-\mathrm{mL}$ iodine bottle containing a $10 \mathrm{~mL} \mathrm{HCl}$ solution $(1+9)$. It was heated to boiling for $30 \mathrm{~s}$ and cooled to room temperature. Then a $50 \mathrm{~mL} 0.1 \mathrm{~mol} \cdot \mathrm{L}^{-1}$ iodine solution was added to it and the mixture was shaken for $15 \mathrm{~min}$, keeping the lid on, and filtered into a dry beaker. Then the $10-\mathrm{mL}$ filtrate was removed with a pipette and moved into a $250-\mathrm{mL}$ iodine bottle, adding $100 \mathrm{~mL}$ of distilled water to it and titrating it with a solution of $0.1 \mathrm{~mol} \cdot \mathrm{L}^{-1}$ sodium thiosulfate. When the solution became yellow, a 2-mL starch indicator was added and it was titrated to a colorless solution. The volume of the sodium-thiosulfate solution was recorded.

\section{RESULTS AND DISCUSSION}

\subsection{Changes in the iodine value of the activated carbon}

The iodine value is the numerical value, representing the amount of the adsorbed iodine in a standard iodine solution, generally used to indicate the adsorption capacity of activated carbon with respect to small molecular impurities. The higher the iodine value, the better the adsorption effect of activated carbon. Our experiment shows that the iodine value of the activated carbon after its modification with potassium permanganate was increased by $1.4505 \%$, that is, the adsorption capacity of the activated carbon was increased.

\subsection{Comparison of the formaldehyde amounts in the room before and after the activated-carbon adsorption}

The amount of formaldehyde in the room was detected through multi-point control (master bedroom, secondary bedroom, study room, living room). The amount of formaldehyde above $0.10 \mathrm{mg} \cdot \mathrm{m}^{-3}$ exceeds the standard. The average amount of formaldehyde in the room before the experiment was $0.14 \mathrm{mg} \cdot \mathrm{m}^{-3}$. The average amount of formaldehyde after the activated-carbon adsorption was $0.1 \mathrm{mg} \cdot \mathrm{m}^{-3}$. The average amount of formaldehyde was further reduced to $0.08 \mathrm{mg} \cdot \mathrm{m}^{-3}$ after the adsorption of the modified activated carbon. The experimental results show that the effect of the activated carbon loaded with potassium permanganate on the indoor formaldehyde was significantly better than that of the unmodified activated carbon.

\subsection{Analysis with field-emission scanning electron microscopy}

Figure 1 includes SEM images of the powdered activated carbon. From Figure 1, it can be seen that the size of the powdered-activated-carbon particles is not uniform and has a strip distribution. From SEM 1a, it can be seen that the size of many activated-carbon particles is about $45 \mu \mathrm{m} \times 30 \mu \mathrm{m}$, the surface is smooth, and a lot of white matter is attached to it. Figure 2 includes the images before the adsorption of potassium-permanganate activated carbon. It can be seen from Figure 2 that the activated carbon after the potassium-permanganate modification is massive, rough and uneven. Figure 3 shows the activated carbon loaded with potassium permanganate. From Figure 3, it can be seen that after the adsorption of the activated carbon modified by potassium permanganate, there is a coral-like distribution observed with the scanning electron microscope. There are many fine particles and obvious pores on the surface. According to the comparison between Figures $\mathbf{2}$ and 3, the morphologies of the activated carbon before and after the modification were very different. 
Z. WU et al.: EFFECT OF POTASSIUM-PERMANGANATE MODIFICATION ON THE MICROSTRUCTURE ...

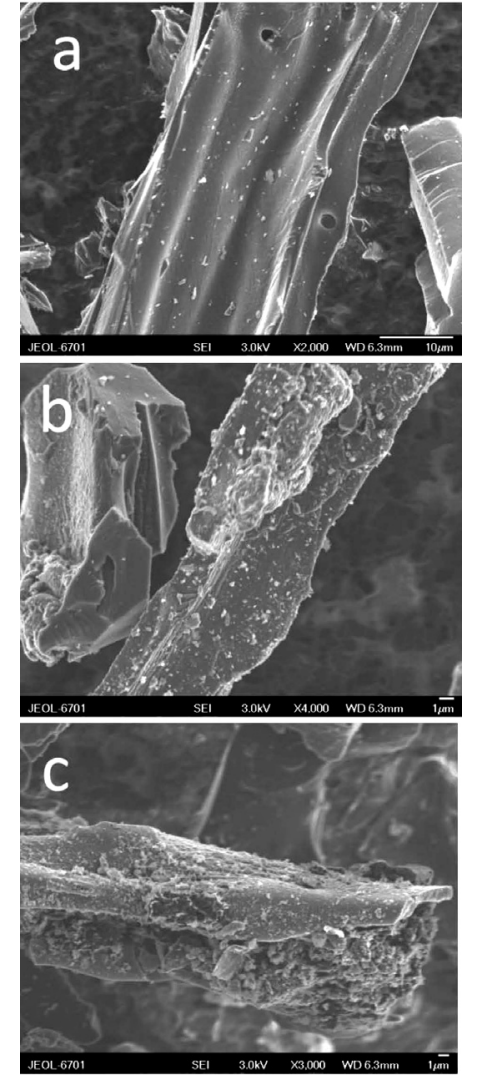

Figure 1: SEM images of the activated carbon
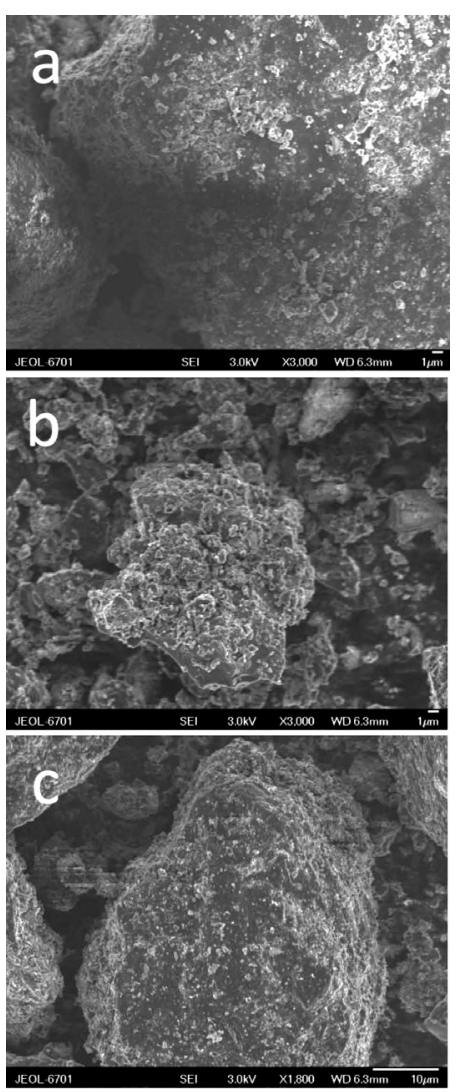

Figure 2: SEM images of the potassium-permanganate-modified activated carbon before the formaldehyde adsorption
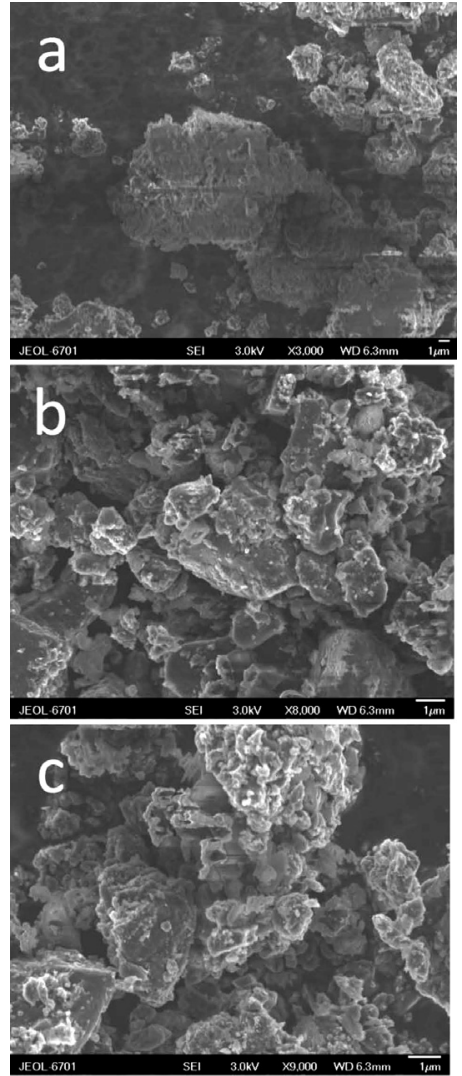

Figure 3: SEM images of the potassium-permanganate-modified activated carbon after the formaldehyde adsorption

\subsection{Powder X-ray diffraction}

Figure 4 shows XRD patterns of the three samples. It can be seen from the diagram that the diffraction patterns are burry, indicating that the particles are very small. The three samples have three strong diffraction peaks belonging to the activated carbon at $2 \theta$ being $27^{\circ}, 44^{\circ}$ and $60^{\circ}$, and there is no difference between the XRD diagrams of the activated carbon without potassium permanganate and the activated carbon loaded with

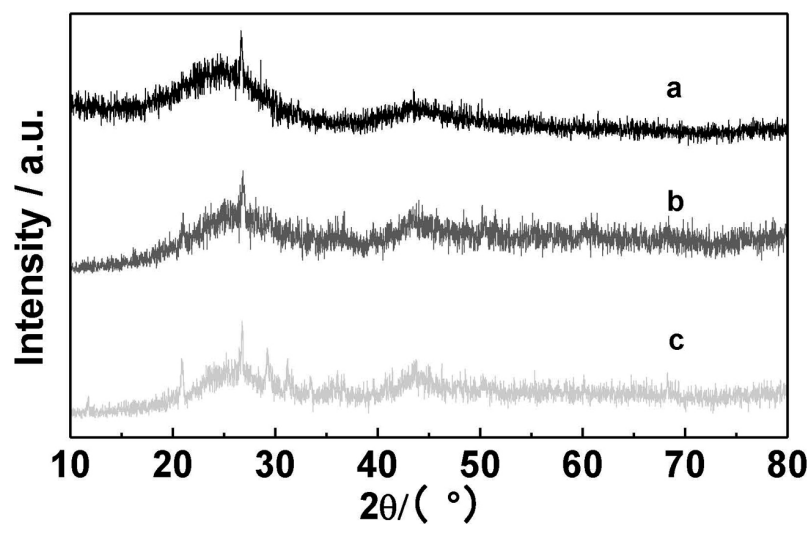

Figure 4: XRD patterns of the three samples: a) powdered activated carbon, b) activated carbon, c) activated carbon loaded with potassium permanganate 
potassium permanganate. When compared with the standard material database, the JCPDS of this kind of C is 89-8487, which indicates that potassium permanganate is in isolation. The loading of potassium permanganate onto the activated carbon did not change the lattice structure of the carbon. The adsorption of formaldehyde is part of the chemical process.

\subsection{Specific surface area and porosity analysis $\left(N_{2}\right.$ ad- sorption)}

Figure 5 shows nitrogen-adsorption isotherms for the activated-carbon samples. The powdered activated carbon is labeled as $\mathbf{5 a}$, and the activated carbon loaded with potassium permanganate is labeled as $\mathbf{5} \mathbf{b}$. Generally speaking, the initial stage of an adsorption isotherm represents the micropore filling of $\mathrm{N}_{2}$, and the adsorption isotherm rises rapidly at a low relative pressure. The superposition of the adsorption force field in pore walls leads to a significant increase in the adsorption potential of micropores. This superposition effect occurs in a narrow aperture range. The superposition effect does not exist in mesoporous and large pores, thus the micropores are the main site for an adsorbate. Adsorption occurs on the mesoporous and large pores and outer surfaces at a high relative pressure, and capillary condensation occurs in mesopores; thus, the level of adsorption increases and the isotherm continues to rise. When $P / P_{0}$ is greater than 0.2 , pores and macropores adsorb a small amount, and the isotherm rises slowly. When $P / P_{0}$ is close to 1 , the adsorbate fills in macropores due to capillary condensation, and a small increase in the isothermal line occurs.

Line $5 \mathrm{a}$ is a type-fourth isotherm with a hysteresis loop. When the relative pressure is less than 0.2 , the adsorption capacity of activated carbon with respect to $\mathrm{N}_{2}$ is smaller. When the relative pressure is greater than 0.2 , the adsorption capacity of the activated carbon with respect to $\mathrm{N}_{2}$ increases with the increase in the pressure, but this trend slows down, indicating the existence of

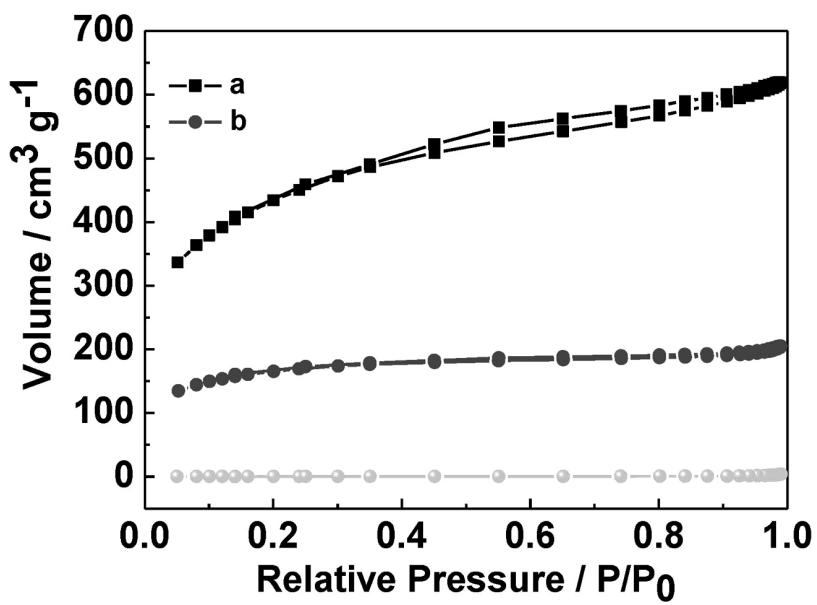

Figure 5: $\mathrm{N}_{2}$ adsorption isotherms: a) activated carbon, b) modified activated carbon

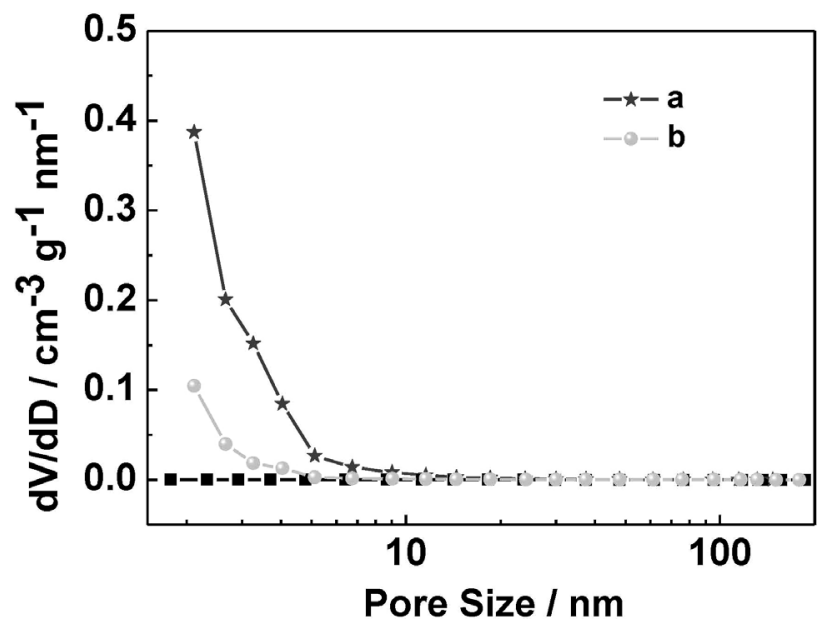

Figure 6: Pore-size and pore-volume-distribution curves of the activated carbon:a) before the adsorption, b)after the adsorption

mesopores in the activated carbon. The interaction force between the potassium-permanganate-activated carbon and $\mathrm{N}_{2}$ is strong, and there are abundant micropores in the activated carbon. Line $5 \mathrm{~b}$ shows the micropore filling characteristic of a type-one isotherm, and the limit adsorption amount is the measure of the micropore volume, indicating an extremely high surface absorption. When the relative pressure is $0.2-1.0$, there is a straight line as the adsorption and desorption lines are basically not separated.

Figure 6 shows the pore-size distribution of the activated carbon and modified activated carbon. The powdered activated carbon is labeled as $\mathbf{6 a}$ and the activated carbon loaded with potassium permanganate is labeled as $\mathbf{6 b}$.

It can be seen from Figure 6 that the pore-size distribution of the two activated carbons is mainly concentrated below $10 \mathrm{~nm}$. The average pore size of the activated carbon and activated carbon loaded potassium permanganate is below $10 \mathrm{~nm}$, but the average pore size of the latter is smaller than that of the former.

\subsection{Analysis with transmission electron microscopy}

Figure 7 shows the transmission-electron-microscope results for the powdered activated carbon used in the experiment. Figure 8 shows transmission-electronmicroscope results before the adsorption of the activated carbon loaded with potassium permanganate. Figure 9 shows transmission-electron-microscope results after the absorption of the activated carbon loaded with potassium permanganate.

From Figure 7, it can be seen that the powdered activated carbon is distributed in a strip, and 7a shows a tiny active-carbon particle of about $1 \times 0.5 \mu \mathrm{m}$; its surface is rough and uneven. Figure $\mathbf{7 b}$ is a magnified image of $7 \mathbf{a}$, showing the existence of pores in the activated carbon. It can be seen from Figures $\mathbf{8 a}$ and $\mathbf{8 b}$ that the 
morphology of the activated carbon after the potassiumpermanganate modification is not very different from that in Figure 7, and there are pores of about $2 \mathrm{~nm}$. However, the amount of micropores displayed in Figure $\mathbf{8 c}$ is obviously increased, which is due to the etching of the activated carbon carried out with potassium permanganate.

As can be seen from Figures $9 \mathbf{a}$ and $\mathbf{9 b}$, no obvious holes were observed in the activated carbon loaded with potassium permanganate, but the amount of micropores shown in Figure 9c is larger than those from Figures 7c and $\mathbf{8 c}$, and the pore size is further reduced to below 2 $\mathrm{nm}$. By comparing Figures $\mathbf{7}$ and $\mathbf{8}$, it can be seen that the morphology of the activated carbon changed greatly. Figure 10 shows a schematic diagram of the micropore change of the activated carbon. The decrease in the pore volume is smaller than that of the total pore volume, resulting in an increase in the percentage of the total pore volume of micropores.
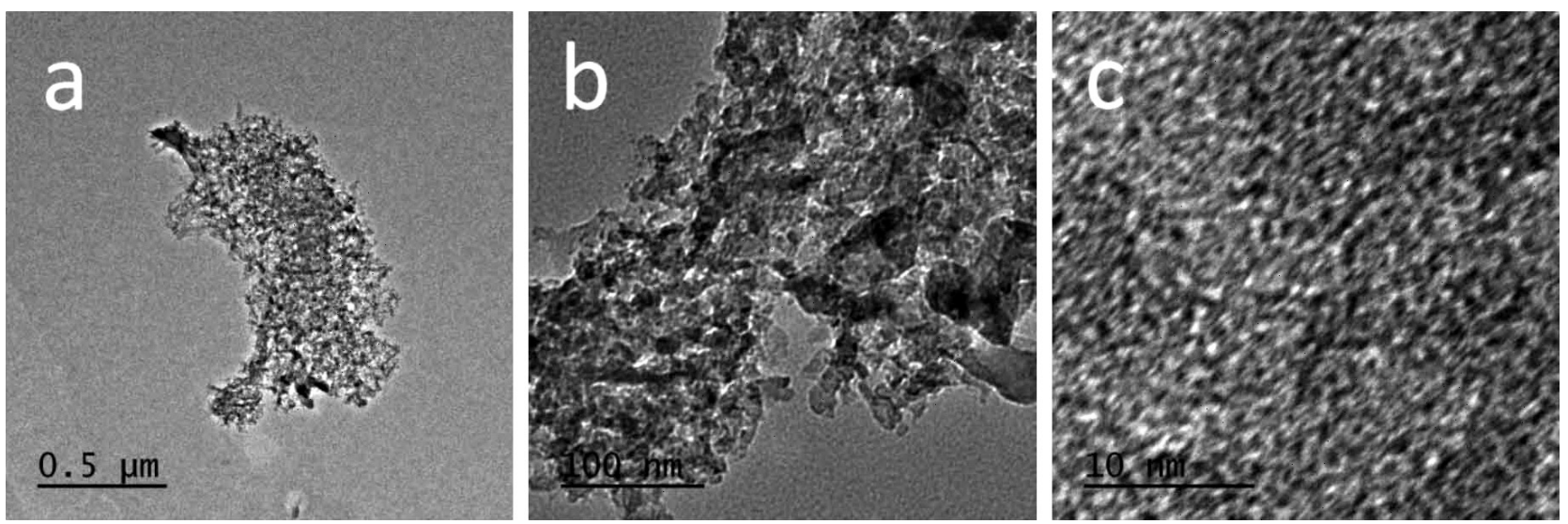

Figure 7: TEM images of the activated carbon
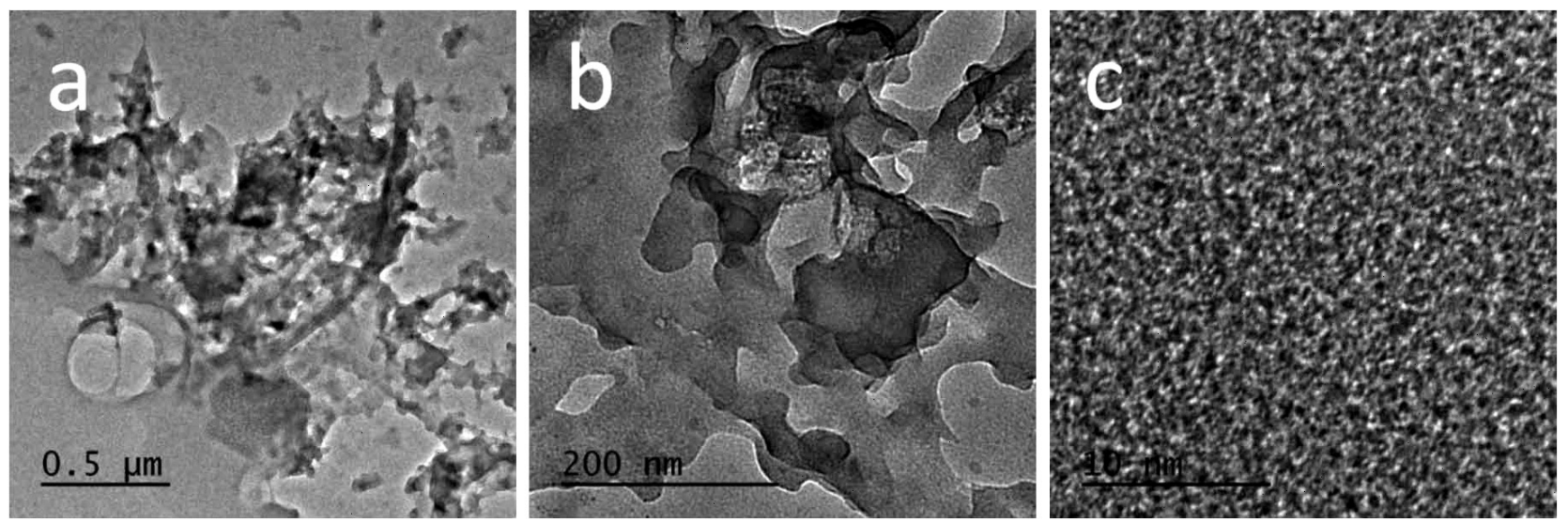

Figure 8: TEM images before the adsorption of formaldehyde onto the potassium-permanganate-modified activated carbon
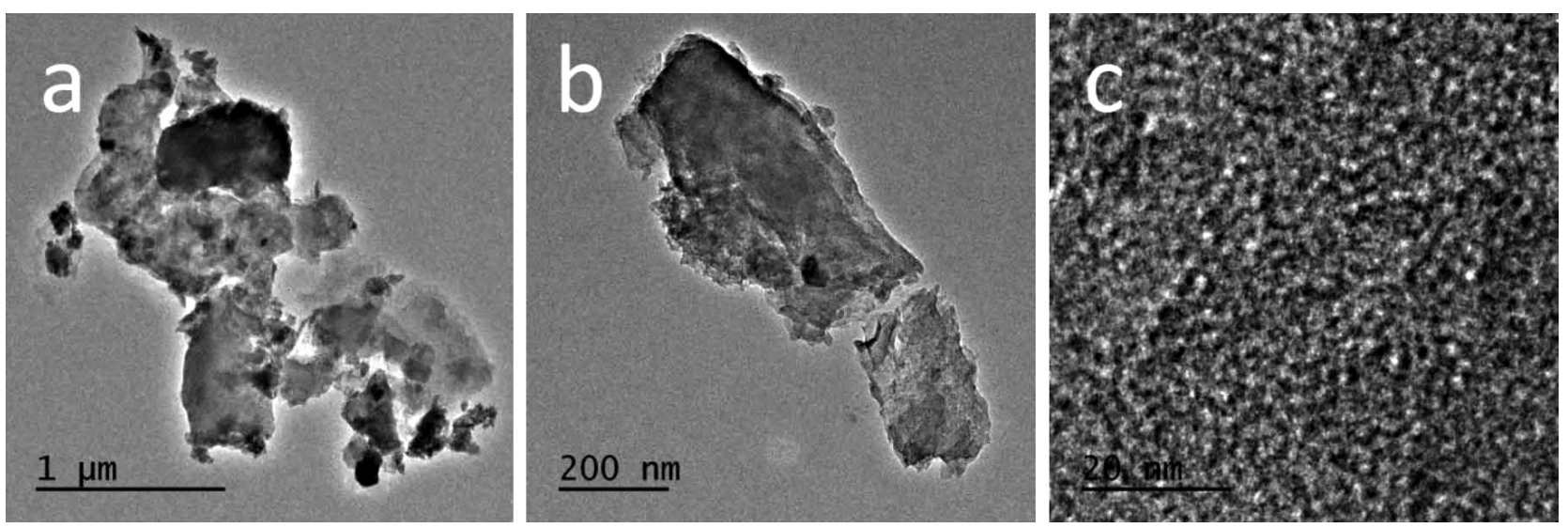

Figure 9: TEM images of the potassium-permanganate-modified activated carbon after the formaldehyde adsorption 


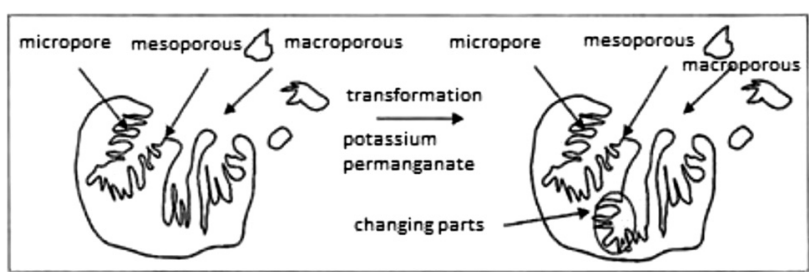

Figure 10: Schematic diagram of the pore-size change of the activated carbon before and after the potassium permanganate etching

\section{CONCLUSIONS}

The activated carbon loaded with potassium permanganate can be used to adsorb indoor formaldehyde, and the effect is obvious. First, formaldehyde molecules are adsorbed on the surface of the activated carbon, then they gradually permeate and aggregate into micropores. Some molecules remain in the micropores, some react with potassium permanganate loaded on the activated carbon, forming carbon dioxide and water, thus degrading completely. The adsorption capacity of the potassium-permanganate-modified activated carbon with respect to indoor formaldehyde is significantly better than that of the unmodified activated carbon. It effectively eliminates the effect of indoor formaldehyde on people's health.

\section{Acknowledgments}

This work was supported by the National Natural Science Foundation of China (No.21665001), the Characteristic Research Team for Aluminum Matrix Composite Materials of the Baise University (081005002), Guangxi College's and University's Key Subject of Material Physics and Chemistry (090106001), the Construction Funds of the Master's Degree Granting Units from the Guangxi Zhuang Autonomous Region for 2019 and the Municipal People's Livelihood Science and Technology Security Special Project of the Xingtai City in 2018 (2018ZZ18).

\section{REFERENCES}

${ }^{1}$ D. Bourdin, P. Mocho, V. Desauziers, H. Plaisance, Formaldehyde emission behavior of building materials: on-site measurements and modeling approach to predict indoor air pollution, J. Hazard. Mater., 280 (2014), 164-173, doi:10.1016/j.jhazmat.2014.07.065

${ }^{2}$ J. Li, H. Jia, Y. Ding, H. Luo, S. Abbas, Z. Liu, L. Hu, C. Tang, $\mathrm{NaOH}$-embedded three-dimensional porous boron nitride for efficient formaldehyde removal, Nanotechnology, 26 (2015) 47, 475704, doi:10.1088/0957-4484/26/47/475704

${ }^{3}$ P. Bourgeois, E. Puzenat, L. Peruchon, F. Simonet, D. Chevalier, E. Deflin, C. Brochier, C. Guillard, Characterization of a new photocatalytic textile for formaldehyde removal from indoor air, Appl. Catal. B-Environ., 128 (2012) 3, 171-178, doi:10.1016/j.apcatb. 2012.03.033

${ }^{4}$ L. Nie, J. Yu, M. Jaroniec, F. F. Tao, Room-temperature catalytic oxidation of formaldehyde on catalysts, Catal. Sci. Technol., 6 (2016) 11, 3649-3669, doi:10.1039/C6CY00062B
${ }^{5}$ S. Nuasaen, P. Opaprakasit, P. Tangboriboonrat, Hollow latex particles functionalized with chitosan for the removal of formaldehyde from indoor air, Carbohyd. Polym., 101 (2014), 179-187, doi:10.1016/j.carbpol.2013.09.059

${ }^{6}$ R. Xiao, J. Mo, Y. Zhang, D. Gao, An in-situ thermally regenerated air purifier for indoor formaldehyde removal, Indoor Air, 28 (2017) 2, 266-275, doi:10.1111/ina.12441

${ }^{7}$ D. Z. Zhao, C. Shi, X. S. Li, A. M. Zhu, B. W. Jang, Enhanced effect of water vapor on complete oxidation of formaldehyde in air with ozone over MnOx catalysts at room temperature, J. Hazard. Mater., 239-240 (2012), 362-369, doi:10.1016/j.jhazmat.2012.09.009

${ }^{8}$ B. Zhu, X. S. Li, P. Sun, J. L. Liu, X. Y. Ma, X. B. Zhu, A. M. Zhu, A novel process of ozone catalytic oxidation for low concentration formaldehyde removal, Chinese J. Catal., 38 (2017) 10, 1759-1769, doi:10.1016/S1872-2067(17)62890-0

${ }^{9}$ X. B. Zhu, C. Jin, X. S. Li, J. L. Liu, Z. G. Sun, C. Shi, X. G. Li, A. M. Zhu, Photocatalytic formaldehyde oxidation over plasmonic $\mathrm{Au} / \mathrm{TiO}_{2}$ under visible light: moisture indispensability and light enhancement, ACS Catal., 7 (2017) 10, 6514-6524, doi:10.1021/ acscatal.7b01658

${ }^{10}$ J. J. Yang, D. X. Li, Z. J. Zhang, Q. L. Li, H. Q. Wang, A study of the photocatalytic oxidation of formaldehyde on $\mathrm{Pt} / \mathrm{Fe}_{2} \mathrm{O}_{3} / \mathrm{TiO}_{2}$, J. Photoch. Photobio. A, 137 (2000) 2-3, 197-202, doi:10.1016/ S1010-6030(00)00340-3

${ }^{11}$ J. G. Yu, S. H. Wang, J. X. Low, W. Xiao, Enhanced photocatalytic performance of direct Z-scheme $\mathrm{g}-\mathrm{C}_{3} \mathrm{~N}_{4}-\mathrm{TiO}_{2}$ photocatalysts for the decomposition of formaldehyde in air, Phys. Chem. Chem. Phys., 15 (2013) 39, 16883-16890, doi:10.1039/c3cp53131g

${ }^{12}$ J. J. Yang, D. X. Li, Q. L. Li, Z. J. Zhang, H. Q. Wang, Mechanism of photocatalytic oxidation of formaldehyde, Acta Phys.-Chim. Sin., 17 (2001) 3, 278-281, doi:10.3866/PKU.WHXB20010320

${ }^{13}$ Y. Huang, S. S. H. Ho, Y. F. Lu, R. Y. Niu, L. F. Xu, J. J. Cao, S. C. Lee, Removal of indoor volatile organic compounds via photocatalytic oxidation: a short review and prospect, Molecules, 21 (2016) 1, 56, doi:10.3390/molecules 21010056

${ }^{14}$ D. Kibanova, M. Sleiman, J. Cervini-Silva, H. Destaillats, Adsorption and photocatalytic oxidation of formaldehyde on a clay- $\mathrm{TiO}_{2}$ composite, J. Hazard. Mater., 211-212 (2012), 233-239, doi:10.1016/j.jhazmat.2011.12.008

${ }^{15}$ H. Rong, Z. Ryu, J. Zheng, Y. Zhang, Effect of air oxidation of Rayon-based activated carbon fibers on the adsorption behavior for formaldehyde, Carbon, 40 (2002) 13, 2291-2300, doi:10.1016/ S0008-6223(02)00109-4

${ }^{16}$ S. Sun, J. Ding, J. Bao, C. Gao, Z. Qi, C. Li, Photocatalytic oxidation of gaseous formaldehyde on $\mathrm{TiO}_{2}$ : an in situ DRIFTS study, Catal. Lett., 137 (2010) 3-4, 239-246, doi:10.1007/s10562-010-0358-4

${ }^{17}$ X. Huang, M. Lin, M. Liao, X. Zhou, J. Li, L. Du, Research regress on removal of formaldehyde by ornamental plant, Modern Agricultural Science and Technology, (2015) 2, 174-175, doi:10075739(2015)02-0174-02

${ }^{18}$ M. Liu, L. Zhang, M. Xiong, L. Zhang, C. Zhang, Research on air purification of indoor foliage plants, Chemical Engineer, 27 (2013) 10, 34-36, doi:10.16247/j.cnki.23-1171/tq.2013.10.004

${ }^{19}$ K. J. Lee, M. Jin, N. Shiratori, S. H. Yoon, J. Jang, Toward an effective adsorbent for polar pollutants: formaldehyde adsorption by activated carbon, J. Hazard. Mater., 260 (2013) 1, 82-88, doi:10.1016/j.jhazmat.2013.04.049

${ }^{20} \mathrm{C}$. Ma, X. Li, T. Zhu, Removal of low-concentration formaldehyde in air by adsorption on activated carbon modified by hexamethylene diamine, Carbon, 49 (2011) 8, 2873-2875, doi:10.1016/j.carbon. 2011.02.058

${ }^{21}$ S. C. Hu, Y. C. Chen, X. Z. Lin, A. Shiue, P. H. Huang, Y. C. Chen, S. M. Chang, C. H. Tseng, B. Zhou, Characterization and adsorption capacity of potassium permanganate used to modify activated carbon filter media for indoor formaldehyde removal, Environ. Sci. Pollut. R., 25 (2018) 28, 28525-28545, doi:10.1007/s11356-018-2681-z 